DOI: https://doi.org/10.24867/09GI07Pajic

\title{
ULOGA ZAPOSLENIH U PROCESIMA BRENDIRANJA PREDUZEĆA BEST SEED PRODUCER DOO
}

\section{THE ROLE OF EMPLOYEES IN BRANDING PROCESS IN A CASE OF COMPANY BEST SEED PRODUCER}

\author{
Srđan Pajić, Fakultet tehničkih nauka, Novi Sad
}

\begin{abstract}
Oblast - INŽENJERSKI MENADŽMENT
Kratak sadržaj - Cilj brendiranja jeste uspostavljanje dugotrajnih odnosa sa potrošačima, te se funkcija brend menadžmenta određuje kao proces izgradnje lojalnosti potrošača prema brendu. Veliku ulogu u ovom procesu imaju ljudski resursi, od čijih veština, znanja, sposobnosti, lojalnosti $i$ sličnih osobina zavisi i pozicioniranje brenda. Ovaj rad ističe značaj menadžmenta ljudskih resursa $u$ marketinga $i$ bavi se istraživanjem uloge zaposlenih u procesu stvaranja i izgradnje brenda.
\end{abstract}

Ključne reči: brend menadžment, vrednost brenda, menadžment ljudskih resursa.

Abstract - The goal of branding is to establish longlasting relationships with consumers, and the function of brand management is defined as the process of building consumer loyalty to the brand. Human resources play an important role in this process, on which the positioning of the brand depends on the skills, knowledge, abilities, loyalty and similar qualities. Considering the importance of human resource management, the paper explores the role of employees in the process of creating brand.

Keywords: brand management, brand values, human resource management

\section{UVOD}

Savremeno doba nosi sa sobom brz protok informacija pa za svakog potrošača, brend predstavlja kompas prilikom donošenja odluke o kupovini datog proizvoda. Poučeni dobrim iskustvom o kupovini nekog proizvoda, potrošači ponavljaju svoju kupovinu na osnovu čega se gradi lojalnost, odnosno najvažnija veza između korisnika i brenda.

Cilj rada odnosi se na proširenje spoznaja o ulozi zaposlenih u brendiranju preduzeća. Cilj istraživanja je prikupiti, obraditi i diskutovati o informacijama koje se odnose na ulogu zaposlenih u brendiranju preduzeća Best SeedProducerdoo.

Predmet istraživanja se odnosi na proces internog brendiranja sa specifičnostima brendiranja zaposlenih i poslodavaca, kao i uticaj internih aktivnosti zaposlenih na ove procese. Glavno istraživačko pitanje je na koji način i u kolikoj meri zaposleni utiču na proces brendiranja jedne kompanije?

\section{NAPOMENA:}

Ovaj rad proistekao je iz master rada čiji mentor je bila doc. dr Jelena Spajić.

\section{POJMOVNO ODREĐENJE BRENDA}

Brendiranje predstavlja ,unapređenje nečega što je sasvim obično i poboljšanje istog kako bi ono postalo vrednije i smislenije" [1].Tradicionalno shvatanje brenda na relaciji kupac-proizvod ili usluga je prevaziđen. Brend danas doživljava ekspanziju upravo zbog velike količine proizvoda i usluga koje se nude na tržištu te se ostavlja mogućnost kupcu da u mnoštvu istih izabere baš onaj spram njegovih potreba.

Pametno osmišljen brend je prednost za svaku kompaniju u trci na globalnom tržištu. Brend je ostao ključno pitanje u svakom preduzeću. On funkcioniše tako što olakšava i vrši efikasniji proces izbora iz ugla potrošača. Sa druge strane, brend sa stanovišta proizvođača, dodaje proizvodu vrednost i na kraju povećava profit kompanije. Prva tradicionalna definisanja prihvaćena od strane Američke marketing asocijacije (American Marketing Association) ukazuju na to da je brend ,ime, pojam znak, simbol ili dizajn, ili pak kombinacija navedenog, čime se identifikuje roba ili usluga jednog prodavca ili grupe prodavaca i diferenciraju u odnosu na konkurente“" [2].

Smatrajući da brend nije samo znak ili simbol nekog proizvoda, savremenije definicije danas uvode novi pojam $\mathrm{u}$ definisanje brenda, a to je dodatna vrednost. Uspešan brend je proizvod, usluga, osoba ili mesto koje možemo da identifikujemo i koji su 'uvećani' na takav način da kupac ili korisnik dobijaju relevantne, jedinstvene dodatne vrednosti koje najviše zadovoljavaju njihove potrebe. Štaviše, njegov uspeh rezultira mogućnost da se ove dodate vrednosti očuvaju u odnosu na konkurenciju [3]. „Svrha brenda suštinski je ista na industrijskom i potrošačkom tržištu. Brendovi omogućavaju indentifikaciju i diferencijaciju proizvoda, usluga i organizacija, u odnosu na konkurenciju“" [4].

\subsection{Vrednost brenda}

Kao značajna komponenta aktive svake kompanije, vrednost brenda nema svoju preciznu metodologiju izračunavanja. Iako se precizni podaci ne mogu izvesti kada je u pitanju vrednovanje brenda, izvođenje procentualnih parametara je od bitne važnosti za kreiranje strategije i budžeta za izgradnju brenda.

Na strategiju i odluke koje se donose u okvirima brend menadžmenta od velikog uticaja može ubiti upravo ovo vrednovanje i parametri dobijeni vrednovanjem svake komponente brenda njenoj ukupnoj vrednosti. 
Keller i Lehmann ističu da vrednost brenda leži u svesti potrošača $\mathrm{i}$ da ako ta svest nije prevedena $\mathrm{u}$ pozitivne stavove potrošača, neće imati velikog uticaja na samu vrednost kompanije odnosno njenih akcija na tržištu. Realni pokazatelj vrednosti neke kompanije određuje njena marketinška imovina kao što je brend, poznavanje tržišta, partnerstvo, bilans stanja, odnos sa potrošačima [5].

\section{INTERNA KOMUNIKACIJA}

Ciljno i razumljivo prenošenje poruka, ideja, misli i znakova među ljudima označava proces komuniciranja [6]. Od efikasnosti upravo ovog procesa zavisi i uspešnost funkcionisanja jedne organizacije. Najprostije rečeno interna komunikacija je komunikacija između ljudi koji čine jednu zajednicu ili organizaciju [7].Na zadovoljstvo i motivaciju radnika, efikasnost, kao i na vrednost kompanije, robne marke utiče dobra interna komunikacija. Osnov dobrog strateškog razmišljanja jeste ulaganje $u$ ljudske resurse i internu komunikaciju [8]. Da bi se razumela interna komunikacija jednog preduzeća potrebno je analizirati i organizacionu kulturu.

Organizaciona kultura može se definisati kao zajednički sistem vrednosti ili normi ponašanja u kompaniji [9]. Proučavanje organizacione kulture bitna je stavka zbog uticaja na model odnosa sa javnošću koji samo preduzeće koristi, kao i na internu komunikaciju koja mu sledi [8].

Zadatak svakog menadžera jeste da nadgleda i osluškuje kako diše interna javnost u okviru kompanije, odnosno njihov najvažniji kapital i vrednost kompanije a to su zaposleni. Osnovni oblici internog komuniciranja su formalni i neformalni, posredni i neposredni, jednosmerni i dvosmerni [8].

\section{INTERNO BRENDIRANJE}

Brendiranje mora biti integrisano u svaki proces poslovanja. Stoga je interno brendiranje veoma bitna disciplina iz ugla organizacije, a sve u cilju daljeg rasta, i napretka iste. Svaki element organizacije treba da na adekvatan način bude posvećen brendu. Zaposleni predstavljaju prvi kontakt i raspolažu sa velikim brojem informacija. Upravo njihova iskustva, interakcija i kontakt sa klijentima treba da budu preneseni na adekvatan način na kupce. Zato vlada stav da su zaposleni srce kompanije [10]

Interno brendiranje je mera korporativne strategije kojom se motivišu zaposleni ne samo da drže obećanje vezano za brend nego da ga na adekvatan način i sprovedu. Da bi to učinile, kompanije uključuju zaposlene u proces razvoja brenda, informišu ih o brendu i podstiču njihov entuzijazam za brend, kako bi na kraju uticali na njihovo ponašanje i predstavljanja brenda. Interno brendiranje je posebno važno jer brendovi rastu kako iznutra tako i spolja i doprinose povećanoj prodaji.

Za svaku organizaciju je od presudnog značaja da njeni zaposleni imaju istu percepciju o brendu i na taj način budu sposobni da istu prenesu na poslovne kupce. Ako svest o brendu ne postoji kod zaposlenih ne može se očekivati da će oni na adekvatan način prezentovati organizaciju i uveriti kupce u kvalitet proizvoda ili usluge. Percepcija o brendu može se stvoriti raznim treninzima i obukama, koji je važan iz dva razloga [11]:
- Zaposleni koji percipiraju svoj trening i obuku pozitivno, verovatnije će percipirati i korporativni brend pozitivno,

- Trening podiže zadovoljstvo i moral zaposlenih i unapređuje njihove veštine.

\section{ZNAČAJ LJUDSKIH RESURSA U BRENDIRANJU}

Uspeh preduzeća zavisi i od pojedinačnih aktivnosti menadžmenta ljudskih resursa, a to su: planiranje, regrutovanje, selekcija, nagrađivanje i dr. [12]. Dobra strategija i efikasnost menadžmenta ljudskih resursa ogleda se u optimalnoj proceni o potrebnom broju ljudskog potencijala, njihovoj adekvatnoj obuci u cilju sticanja novih znanja i veština, praćenje rezultata rada $i$ na adekvatan način uspostavljanje kriterijuma za ocenjivanje, uspostavljanje vrednosnih sistema koja će i privući ali i zadržati zaposlene, jača međuljudske odnose i motiviše zaposlene.

Savremeni načini upravljanja organizacijama sve više pridaju značaj upravljanju ljudskim resursima. Značaj ljudskih resursa ogleda se u činjenici da ljudski potencijal predstavlja vredan resurs savremene organizacije, kao i ključna stavka njene konkurentske prednosti. Ljudski potencijal ogleda se u znanju, veštinama, stručnim iskustvom i za jednu organizacije oni su kako stvaralačka snaga tako i pokretačka. Njihova uloga i značaj je presudna $\mathrm{u}$ procesima proizvodnje, promena, stvaranje nove dodatne vrednosti, efikasnosti rada i slično. Od njihove organizacije i sposobnosti za rad, radnih navika, kreativnosti, motivisanosti zavisi i funkcionisanje organizacije ali i ispunjenje postavljenih ciljeva. Zadatak uspostavljanja optimalne kadrovske strukture je u rukama odgovarajuće menadžerske strukture. Njihov cilj je uspostavljanje ravnoteže u broju i strukturi poslovanja, promenama, funkcionisanja kolektiva i sl. Da bi kadrovska struktura bila optimalna svaki zaposlen mora biti raspoređen na ono radno mesto koje odgovara njegovim sposobnostima i kvalifikaciji. Ključan faktor $u$ upravljanju ljudskim resursima jeste da se sve aktivnosti usmere ka uspehu kompanije [12].

\subsection{Uloga zaposlenih u brendiranju}

Značaj posedovanja jakog brenda ima za posledicu dobru reputaciju, a samim tim i dobre odnose sa dobavljačima, medijima, lokalnom zajednicom, finansijskim posrednicima i sl. Ovako stečena reputacija utiče i na privlačenje talenata, koji za jednu kompaniju znači novo znanje i mogućnost napredovanja. Jaki brendovi ne privlače samo potrošače, već i zaposlene koji se identifikuju sa njima i na taj način postaju motivisani da bolje rade i stvaraju dodate vrednosti. Za brend menadžere dobro je poznata rečenica „Najbolji brendovi privlače najbolje talente“ [13].

Kao nova perspektiva tumačenja kapitalnih vrednosti brenda pojavljuje se uloga zaposlenih. Novi koncept stvaranja dodate vrednosti sa sve većom ulogom zaposlenih $\mathrm{u}$ istoj označava proces internog brendiranja kompanije. Uloga zaposlenih jeste da poznaju svoj brend, šire svoja znanja o istom te na taj način utiču i na strategijske odluke menadžmenta [13]. 
Na koji način će brend biti reprezentovan utiču mnogi faktori, među njima najviše ljudski faktor odnosno znanje, veštine, sposobnosti, psihološki profil ali i moralni stavovi i vrednosti zaposlenih u kompaniji. Uticaj i stvaranje prednosti i dobre percepcije o brendu kod potrošača itekako imaju zaposleni koji se nalaze ,iza scene", kao što su programeri od kojih zavisi kvalitet softvera nama poznatih kompanija IBM ili Microsoft, takođe kreditni odbor gde se donose odluke o odobrenju kredita ili ne, iza Amazona, Googla nalaze se ljudi koji su osmislili takav koncept i sl.

Svaka njihova odluka utiče i na stvaranje vrednosti brenda. Zato je danas uloga menadžmenta ljudskih resursa, postavljanje pravih ljudi na radna mesta adekvatna njihovim znanjima, veštinama i sposobnostima ključna za uspeh kompanije [14].

Pokazatelj uspešnosti brenda je potrošač koji pozitivno reaguje na vrednost brenda i ostaje lojalan istom. U cilju što višeg rangiranja brenda, zaposleni prihvataju oblike ponašanja u skladu sa vrednosti brenda. Upravo vrednost je ta koja privlači potrošače čije se vrednosti podudaraju sa vrednostima brenda.

Kao primer možemo navesti kompaniju LG, čiji se zaposleni zalažu vrednost brenda kroz kreativnost, poverenje, obazrivost, inovativnost [15]. Još jedan dobar primer su vrednosti brenda Lego: kreativnost, maštovitost, zabava, učenje, brižnost, kvalitet [16].

\section{UTICAJ ZAPOSLENIH NA PROCES BRENDIRANJA PREDUZEĆA NA PRIMERU POSLOVANJA PREDUZEĆA BEST SEED PRODUCER DOO}

Za potrebe rada sprovedeno je istraživanje koje ima za cilj ispitivanje uloga zaposlenih u brendiranju preduzeća Best Seed Producer DOO. Pitanja koja se nalaze u anketi o angažmanu zaposlenih i ulozi u brendiranju preduzeća prolaze kroz proveru eksterne metrike uključujući "Glassdoor ratings" i "Mattermark Growth scores" [17]. Angažovanje zaposlenih predstavlja nivo entuzijazma i povezanosti zaposlenih sa njihovom organizacijom. To je mera koliko motivisani ljudi ulažu dodatne napore za svoju organizaciju i znak koliko su posvećeni da ostanu u istoj. Važno je da angažovanje zaposlenih predstavlja ishod koji zavisi od aktivnosti organizacije, posebno aktivnosti od strane rukovodstva, menadžera i timova ljudi.

Angažovanje zaposlenih ima uticaja na zadržavanje zaposlenih i verovatnoću da zaposleni preporuče svoju kompaniju kao sjajno mesto za posao. Menadžeri često zanemaruju uticaj angažovanja zaposlenih u brendiranju kompanije. Jasno je da kada kompanije interno neguju angažman zaposlenih, oni utiču $i$ na uspeh svoje kompanije. U istraživanju je učestvovalo 51 zaposleni od ukupno 70 zaposlenih u preduzeću Best Seed Producer $D O O$, koji su odgovorili na pitanja iz anketnog upitnika.

$\mathrm{Na}$ osnovu sprovedenog istraživanja dolazi se do zaključka da preduzeće Best Seed Producer doo ima snažnu organizacionu kulturu koja motivaciono deluje na zaposlene i zalaže se za timski rad i saradnju među zaposlenima. Pokazatelj uspešnosti brenda je potrošač koji pozitivno reaguje na vrednost brenda i ostaje lojalan istom. U cilju što višeg rangiranja brenda, zaposleni prihvataju oblike ponašanja u skladu sa vrednosti brenda. Upravo vrednost je ta koja privlači potrošače čije se vrednosti podudaraju sa vrednostima brenda. Rezultati istraživanja u kompaniji Best Seed Producer doo ukazuju da se zaposleni zalažu za vrednost brenda kroz lojalnost, poverenje, obazrivost, dobru komunikaciju, informisanost, mogućnost napretka, obuke I treninga. Razvijen je osećaj pripadnosti u preduzeću i svesti o brendu koji reprezentuju eksternim činiocima. Svaki od ovih činilaca ukazuje na veliku ulogu ljudskih resursa u internom brendiranju.

\section{ZAKLJUČAK}

Iz ugla menadžmenta ljudskih resursa, postoji uzročnoposledična veza između ljudskih resursa i brenda. Vrednosti i standardi koje poseduje brend ima uticaja na izbor, selekciju, regrutaciju ljudskih resursa, sistem nagrađivanja, organizacionu kulturu ali i motivaciju zaposlenih. "Najbolji brendovi, privlače najbolje talente". Samo takav brend se dobro pozicionira na savremenom tržištu i privlači najbolji kadar. Savremena istraživanja ukazuju na to da zaposlene treba posmatrati kao kapital kompanije, kao i to da su zadovoljstvo zaposlenih i potrošača u direktnom odnosu.

Ljudski kapital ima svoju ulogu u brendiranju, sa svim svojim kompetencijama, veštinama, sposobnostima utiču na stvaranje vrednosti brenda. Zato je danas uloga menadžmenta ljudskih resursa postavljanje pravih ljudi na radna mesta u skladu sa njihovim znanjima, veštinama i sposobnostima, ključna za uspeh brendiranja neke kompanije.

$\mathrm{Na}$ osnovu sprovedenog istraživanja dolazi se do zaključka da preduzeće Best Seed Producer doo ima snažnu organizacionu kulturu koja motivaciono deluje na zaposlene i zalaže se za timski rad i saradnju među zaposlenima. Pokazatelj uspešnosti brenda je potrošač koji pozitivno reaguje na vrednost brenda i ostaje lojalan istom.

\section{LITERATURA}

[1] S. Bedberi, Novi svet brendova: 8 principa da postignete brend liderstvo u 21. veku, Beograd: Mass Media International, 2009.

[2] P. Kotler / K. L. Keller, Marketing menadžment, 12 izdanje, Beograd, 2006.

[3] L. De Chernatony / M. McDonald, Creating Powerful Brand in Consumer Servis ans Industrial Markets, Oxford: Butterworth Heinemann, 2003.

[4] J. Anderson / J. A. Narus, Business Market Managament: Understanding, Creating and Delivering Value, New Yersey: Pearson Prentice Hall, 2004.

[5] K. L. Keller / D. R. Lehmann, „Brands and Branding: Research Findings and Futur Priorities, “ November 2006.

[6] M. Paunović / A. Radonjic, ,ZNAČAJ KOMUNIKACIJE U SAVREMENOM POSLOVANJU,“"Megabiznis, 2232018. 
[7] Z. Jurakovic, ,Važnost komunikacije u funkcioniranju organizacije,“ Ekonomski vjesnik, pp. 387-399, 2012.

[8] J. S. Smiljković, „Uloga Interne komunikacija u kompaniji, “ Juornal od Insurance and Practice, p. 134, 2015.

[9] S. Mitić, „Organizational culture and organizational commitment: Serbian case, " Journal of Engineering Management and Competitiveness, 2016.

[10] R. Claessens, „Branding and Corporate culture,“ 18, 30082011.

[11] S. T. Nikolić, . J. Stanković / A. Dejanović, Brend menadžment - savremena a(tra)kcija, Novi Sad: FTN, 2015.

[12] I. Vrgović / J. Đurković, „Merenje doprinosa menadžmenta ljudskih resursa organizacionoj uspešnosti,“ Upravljanje ljudskim resursima savremeni trendovi, pp. 8-17, 2014.

[13] S. Jovanović / I. Vrgović, „Uloga zaposlenih i menadžmenta ljudskih resursa u procesu stavranja vrenodsti brenda,“ Škola biznisa, pp. 41-50, 2017.

[14] D. Torrington, L. Hall / S. Taylor, Menadžment ljudskih resursa, Beograd: Data status, 2004.

[15] LG-Group, „Core Values,“ 2019. [Na mreži]. Available: http://www.lgdisplay.com/eng/recruit/coreValues. [Poslednji pristup 26. 11. 2019.].

[16] Lego-Group, „Lego Corporation,“ 2019. [Na mreži]. Available: http://aboutus.lego.com. [Poslednji pristup 26. 11. 2019.].

[17] J. Matar, „How Employee Engagement Impacts Your Company's Growth,“Brazen, 2017.

\section{Kratka biografija:}

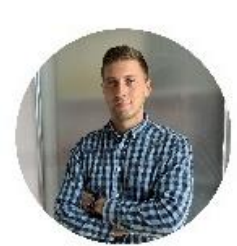

Srđan Pajić rođen je u Šapcu 1989. god. Master rad na Fakultetu tehničkih nauka iz oblasti Inženjerski menadžment Industrijski marketing $\mathrm{i}$ inženjerstvo medija odbranio je 2020.god.

kontakt: pajicsr@yahoo.com 